\title{
Research
}

\section{Use of folic acid supplements and risk of cleft lip and palate in infants:}

\author{
a population-based cohort study
}

\begin{abstract}
\section{Background}

Orofacial clefts occur when the lips or the roof of the mouth do not fuse properly during the early weeks of pregnancy. There is strong evidence that periconceptional use of folic acid can prevent neural tube defects but its effect on oral clefts has generated debate.
\end{abstract}

\section{Aim}

To identify factors associated with suboptimal periconceptional use of folic acid and its potential effect on oral clefts.

\section{Design and setting}

The population-based infant cohort of the national Growing Up in Ireland study, which consists of 11134 9-month-old infants.

\section{Method}

Data collection comprised questionnaires conducted by interviewers with parents in parents' homes. Characteristics of mothers who did or did not take folic acid before and during pregnancy, as well as the effect of folic acid use on the prevalence of cleft lip and palate were recorded.

\section{Results}

The prevalence of cleft lip and palate was 1.98 ( $95 \%$ confidence interval $[\mathrm{Cl}]=1.31$ to 2.99 ) per 1000 9-month-olds. The odds ratio for cleft lip was 4.36 -fold higher $(95 \% \mathrm{Cl}=1.55$ to $12.30, P=$ $0.005)$ for infants of mothers who did not take folic acid during the first 3 months of pregnancy, when compared with those who did have a folate intake during the first trimester. Folic acid use was suboptimal in $36.3 \%$ (95\% Cl $=35.4$ to 37.2 ) of the sample.

\section{Conclusion}

These findings support the hypothesis that taking folic acid may partially prevent cleft lip and palate. They are particularly relevant for GPs, because they are usually the first port of call for women before and during early pregnancy.

\section{Keywords}

cleft lip; epidemiology; folic acid; general practice; infant.

\section{INTRODUCTION}

Orofacial clefts occur when the lips and/or the roof of the mouth do not fuse properly during development, leaving an opening; this occurs between 6 and 9 weeks of pregnancy. Treatment involves plastic surgery, beginning approximately 3 months after birth and continuing into adolescence. The effects on an individual's speech, hearing, appearance, and psychology can lead to long-lasting adverse outcomes for health and wellbeing. Even when repaired, complications such as persistent ear infections, speech impairments, facial deformities, and dental problems often remain. ${ }^{1}$

A cleft lip and palate occurs in approximately one in 700 live births. ${ }^{2}$ Cleft lip, with or without cleft palate, is most frequent in males and isolated cleft palate is most common in females. Prevalence varies according to geography and ethnicity. ${ }^{1}$

The cause of cleft lip and palate is complex but involves both genetic and environmental factors. Genetic studies have demonstrated higher prevalence of cleft lip and palate in monozygotic twin pairs than in twins who are dizygotic, and in siblings in whom congenital anomalies exist. ${ }^{1}$ Environmental factors have been implicated as contributors to cleft lip and palate 1 and include maternal exposure to: tobacco smoke; ${ }^{3}$ alcohol; medicines such as anticonvulsant drugs, notably diazepam, phenytoin, and phenobarbital; 4 illicit drugs;

D Kelly, BSc, MPSI, postgraduate research student; T O'Dowd, MD, FRCGP, professor of general practice; U Reulbach, MSc, FRSPH, clinical research fellow, Department of Public Health and Primary Care, Trinity College Dublin, Dublin, Ireland.

\section{Address for correspondence}

Tom C O'Dowd, Department of Public Health and Primary Care, Trinity College Centre for Health Sciences, Trinity College Dublin, Adelaide \& Meath viral infection; and nutritional deficiencies.

A recent Cochrane review found that folic acid intake before and during early pregnancy can prevent the occurrence of neural tube defects. ${ }^{5}$ There has been huge interest in the potential benefits of folic acid in other areas - such as cardiovascular and urinary tract congenital anomalies ${ }^{6}$ and cleft lip and palate ${ }^{7}$ - although, to date, there has been insufficient evidence to evaluate this. Although the exact mechanism of folic acid in facilitating neural tube closure is unknown, it is estimated that $>70 \%$ of neural tube defects can be prevented by maternal folic acid supplementation. ${ }^{8}$

Women of childbearing age are advised to take an additional $400 \mu \mathrm{g}$ of folic acid daily if there is any possibility of them becoming pregnant, and to continue this for the first 12 weeks of pregnancy. ${ }^{9}$ In practice, the consumption of preventive folic acid has had mixed uptake; it is suggested that unplanned pregnancies may play a pivotal role in hampering success. ${ }^{10}$ Globally, some policy makers have introduced mandatory folic acid fortification of foods due to the benefits to population health; ${ }^{9}$ however, as previous studies have shown that low socioeconomic status (measured by occupation), being a smoker, and unplanned pregnancies are associated with not taking the recommended folic acid supplements, ${ }^{11,12}$ there is still considerable scope for improving folic acid uptake.
Hospital, incorporating the National Children's Hospital, Tallaght, Dublin 24, Ireland.

E-mail: todowdatcd.ie

Submitted: 29 November 2011; Editor's response: 3 January 2012; final acceptance: 10 April 2012. (CBritish Journal of General Practice This is the full-length article (published online 25 June 2012) of an abridged version published in print. Cite this article as: Br J Gen Pract 2012; DOI: 10.3399/bjgp12X652328. 


\section{How this fits in}

Taking folic acid 4 weeks before, and for the first 12 weeks during, pregnancy can prevent neural tube defects. A recent Cochrane review concluded that there was no statistically significant evidence of any effect of folic acid in the prevention of oral clefts. However, this study supports the hypothesis that folic acid taken in the first 12 weeks of pregnancy may significantly reduce the prevalence of cleft lip and palate.

The potential effect of folic acid supplements on preventing oral clefts has generated considerable debate. A recent meta-analysis concluded that maternal multivitamin supplements taken during early pregnancy were associated with a $25 \%$ decreased risk of orofacial clefts; the role of folic acid, however, was far less convincing. ${ }^{13}$ In contrast, Badovinac et al reviewed five prospective studies and 12 case-control studies and concluded that taking a folic acid-containing supplement during pregnancy did have a protective effect against the risk of developing oral clefts. ${ }^{14}$

Further research is necessary to establish the benefits of folic acid supplements in preventing birth defects, other than neural tube defects. The aim of this study was to estimate the prevalence of cleft lip and palate in the 9-month-old Irish population and to assess the effect of folic acid supplement in preventing it.

\section{METHOD}

\section{Study population}

The study involved a cross-sectional analysis of the first wave of data from the infant cohort of the Growing Up in Ireland study. Infants were randomly selected from the Child Benefit Register. A systematic selection procedure, based on a random start and constant sampling fraction, was used..$^{15}$ The 11134 infants representing the 9-month cohort were born between 1 December 2007 and the 30 June 2008.

\section{Data collection and analysis}

Data were collected between September 2008 and April 2009 via questionnaires, conducted by interviewers, that were undertaken with parents in their homes. Inclusion in the study was on an opt-out basis; consent forms were signed by the parent(s)/guardian(s) before the start of the interview: 17264 families were asked to participate in the study.
Analyses were based on statistically reweighted data to ensure they were representative of all 9-month-olds in Ireland. The weighting system aims to compensate for any imbalances in the population recruited. Eleven main characteristics of the infant and his or her family were used in the generation of the weights: family structure; mother's age; mother's principal economic status; father's principal economic status; family's social class; mother's education; household tenure; region; mother's marital status; mother's nationality; and mother's residency status. This method of weighting used is a minimum information algorithm that fits population marginals in a regression framework and adjusts the sample estimates to ensure that they produce estimates that match human population parameters. ${ }^{16}$

The power analysis for the present study was based on the a priori assumption of a 2.5-fold increase of cleft lip and palate in children as threshold when users and nonusers of folate were compared. The a priori estimates of cleft lip and palate was 1 in 700 births and one-third of the population in non-users of folates. Using a type- 1 error estimate of 0.05 and a power of $80 \%$, the sample size calculation yields a required number of 3362 in each group lusers versus non-users of folates). Based on 11000 infants in the cohort, a third lequating to 3666 infants) would be the offspring of nonusers. Therefore, it was concluded that the present study has enough power to detect differences between users and non-users of folates regarding cleft lip and palate.

Cleft lip and palate prevalence was estimated based on the following question, as answered by the primary caregiver:

- Has a medical professional ever told you that the baby has cleft lip and palate?

The questionnaire included two questions to determine use of folic acid; the biological mother was asked:

- Did you take folic acid/folate prior to becoming pregnant with the baby?; and

- Did you take folic acid/folate during the first 3 months of pregnancy with the baby?

In addition, information on maternal and family characteristics was collected, including details of household composition; infant's development; parenting and relationships; the infant's habits; childcare arrangements; siblings and twins; prenatal care; the infant's health; the health of the 
Table 1. Factors associated with not taking folic acid during the first 3 months of pregnancy

\begin{tabular}{|c|c|c|c|c|c|}
\hline \multirow[b]{2}{*}{ Factor } & \multicolumn{2}{|c|}{$\begin{array}{l}\text { Proportion of mothers who } \\
\text { did not take folic acid }\end{array}$} & \multicolumn{3}{|c|}{ Mother not taking folic acid } \\
\hline & $\%$ & $95 \% \mathrm{Cl}$ & AOR & $95 \% \mathrm{Cl}$ & $P$-value \\
\hline \multicolumn{6}{|c|}{ Maternal age, years ( $n=10$ 891), univariate $P<0.001$, multivariate $P=0.042$} \\
\hline$<20$ & 20.4 & 15.4 to 25.5 & 1.36 & 0.80 to 2.33 & 0.256 \\
\hline $20-24$ & 13.2 & 11.4 to 15.4 & 1.14 & 0.76 to 1.70 & 0.528 \\
\hline $25-29$ & 8.1 & 7.0 to 9.3 & 1.01 & 0.70 to 1.46 & 0.964 \\
\hline $30-34$ & 5.3 & 4.6 to 6.0 & 0.93 & 0.65 to 1.33 & 0.672 \\
\hline $35-39$ & 4.2 & 3.5 to 5.0 & 0.72 & 0.49 to 1.06 & 0.094 \\
\hline$\geq 40$ & 5.9 & 4.4 to 7.9 & 1.00 (reference) & & \\
\hline \multicolumn{6}{|c|}{ Highest education attained ( $n=10883$ ), univariate $P<0.001$, multivariate $P<0.001$} \\
\hline Less than lower secondary & 13.9 & 12.5 to 15.6 & 1.80 & 1.19 to 2.71 & 0.005 \\
\hline Lower secondary & 7.5 & 6.2 to 7.8 & 1.18 & 0.80 to 1.76 & 0.404 \\
\hline Leaving Certificate & 4.1 & 3.3 to 5.0 & 1.00 & 0.65 to 1.52 & 0.983 \\
\hline Subdegree & 3.7 & 2.9 to 4.6 & 1.19 & 0.77 to 1.82 & 0.433 \\
\hline Degree or higher & 2.8 & 2.1 to 3.8 & 1.00 (reference) & & \\
\hline \multicolumn{6}{|c|}{ Annual equivalised income ( $n=10$ 094), univariate $P<0.001$, multivariate $P<0.001$} \\
\hline First (lowest-income) quintile & 13.8 & 12.4 to 15.4 & 2.76 & 1.85 to 4.12 & $<0.001$ \\
\hline Second quintle & 9.5 & 8.3 to 10.9 & 2.25 & 1.52 to 3.33 & $<0.001$ \\
\hline Third quintile & 4.3 & 3.5 to 5.3 & 1.29 & 0.86 to 1.95 & 0.219 \\
\hline Fourth quintile & 3.6 & 2.9 to 4.4 & 1.43 & 0.96 to 2.13 & 0.081 \\
\hline Highest quintile & 2.1 & 1.5 to 2.9 & 1.00 (reference) & & \\
\hline \multicolumn{6}{|c|}{ Occupational household class ( $n=10891)$, univariate $P<0.001$, multivariate $P<0.001$} \\
\hline Professional/managerial & 2.9 & 2.5 to 3.4 & 1.00 (reference) & & \\
\hline Other non-manual/skilled, manual & 7.2 & 6.4 to 8.1 & 1.56 & 1.22 to 1.99 & $<0.001$ \\
\hline Semi-skilled/unskilled & 13.7 & 11.7 to 15.9 & 2.52 & 1.88 to 3.37 & $<0.001$ \\
\hline All others employed and unknown & 28.3 & 17.9 to 41.6 & 5.99 & 2.90 to 12.37 & $<0.001$ \\
\hline Never worked at all & 16.9 & 14.7 to 19.4 & 1.89 & 1.33 to 2.68 & $<0.001$ \\
\hline \multicolumn{6}{|c|}{ Household type ( $n=10891$ ), univariate $P<0.001$, multivariate $P=0.010$} \\
\hline One parent, one child $<18$ years & 14.0 & 11.8 to 16.6 & 1.24 & 0.92 to 1.67 & 0.159 \\
\hline One parent, two or more children $<18$ years & 15.2 & 12.9 to 17.8 & 1.08 & 0.81 to 1.43 & 0.610 \\
\hline Two parents, one child $<18$ years & 4.2 & 3.6 to 4.9 & 0.74 & 0.59 to 0.93 & 0.010 \\
\hline Two parents, two or more children $<18$ years & 6.1 & 5.5 to 6.8 & 1.00 (reference) & & \\
\hline
\end{tabular}

parent being interviewed; family context; sociodemographics; household income; and neighbourhood.

As well as univariate analyses (Pearson's $\chi^{2}$ test, Fisher's exact test), multivariate analyses considered factors associated with non-use of folic acid and the effect of folic acid use on the rate of cleft lip and palate. The odds ratio (OR) was adjusted for:

- maternal age (metric);

- household composition (two variables were included: lone parenthood and number of siblings of the study infant);

- highest level of education Ifive categories: less than lower secondary; lower secondary; Leaving Certificate; subdegree; degree or higher);

- equivalised annual income (quintiles);

- occupational household class Iprofessional/managerial; other nonmanual/skilled, manual; semi- skilled/unskilled; all others employed; and unknown/never worked at all);

- urbanicity (urban or rural area);

- smoking lsmoking hazard during pregnancy: how many members of the household smoked including the biological mother); and

- at how many weeks the mother became aware that she was pregnant.

Factors were included in the multivariable models if there was a biologically plausible potential for confounding. Results are reported as ORs and 95\% confidence intervals (Cls) derived from binary logistic regression analyses. The statistical software SPSS (version 19) was used, together with a significance level of $P=0.05$.

\section{RESULTS}

In total 17264 families were approached, and a usable interview was completed with 
11134 (64.5\% response rate). Lone parents and mothers in lower educational categories were under-represented in the unweighted sample.

\section{Prevalence of non-consumption of folic acid}

Over one-third of women $136.3 \%, 95 \% \mathrm{Cl}=$ 35.4 to 37.2) did not take a folic acid supplement before becoming pregnant. During the first trimester of pregnancy, a minority of women $16.7 \%, 95 \% \mathrm{Cl}=6.3$ to 7.2) did not take a folic acid supplement. A significant association $(z=-11.0 ; P<0.001)$ was observed between the number of weeks at which the mother became aware that she was pregnant and taking folic acid during the first 3 months of pregnancy Imedian number of weeks of becoming aware of the pregnancy was 5 weeks for mothers who took folic acid during the first trimester, compared with 6 weeks for mothers who did not take folic acid). In the group of women who became aware of the pregnancy after the first trimester, only one-third took folic acid.

\section{Factors associated with non-consumption} of folic acid

Table 1 outlines the socioeconomic factors that were associated with non-consumption of folic acid during the first trimester. Not taking folic acid was significantly $(P<0.001)$ associated with younger maternal age, lower education, lower income, and lower

\section{palate and use of folic acid in the first}

trimester of pregnancy. Error bars $=95 \%$. occupational household class, and household type. In a multivariate analysis (logistic regression model, Nagelkerke $R^{2}$ 0.110 , Table 1), low maternal education, low household income, and low occupational household class were highly significantly $(P<0.001)$ associated with non-consumption of folic acid.

\section{Prevalence of cleft lip and palate}

The prevalence of cleft lip and palate was $2.0(95 \% \mathrm{Cl}=1.3$ to 3.0) per 1000 9-montholds). Male infants were twice as often affected by cleft lip and palate when compared with female infants lrisk 2.03, $95 \% \mathrm{Cl}=0.83$ to 4.98 , Fisher's exact test, $P$ $=0.136$ [not significant]).

\section{Association between folic acid and cleft lip and palate}

The intake of folic acid during the first 3 months of pregnancy was significantly associated with cleft lip and palate (Fisher's exact test; $P=0.009$, Figure 1). The rate of cleft lip and palate in infants was 6.8 (95\% $\mathrm{Cl}=3.0$ to 15.8 ) per 1000 9-month-olds among those women who did not take folic acid and $1.5(95 \% \mathrm{Cl}=0.9$ to 2.4$)$ per 1000 9month-olds in those women who did take folic acid. The OR (logistic regression) of not having folic acid during the first 3 months of pregnancy for cleft lip was 4.36 -fold higher (95\% Cl $=1.55$ to $12.30, P=0.005)$ when compared with participants who had a folate intake during the first trimester.

In a multivariate logistic model (Nagelkerke $R^{2}=0.133$ ), adjusted for maternal education, age, occupational household class, urbanicity, family structure (lone parenthood and sibship), and smoking hazard in pregnancy, this OR was even slightly higher $(\mathrm{OR} 4.52,95 \% \mathrm{Cl}=$ 1.48 to $13.77, P=0.008$ ). No significant risk increase for cleft lip was observed with taking any folic acid supplement before becoming pregnant $(\mathrm{OR} 1.41,95 \% \mathrm{Cl}=0.58$ to $3.4, P=0.448$ ).

\section{DISCUSSION}

\section{Summary}

Over one-third of mothers did not take folic acid in early pregnancy in this large nationally representative cohort study. The OR for cleft lip palate for infants of such mothers was 4.36-fold higher than for mothers who had taken folic acid in early pregnancy. Current recommendations state that women planning pregnancy should use a folic acid supplement of $400 \mu \mathrm{g}$ per day from at least 4 weeks before, until 12 weeks after, conception. ${ }^{9}$ The consumption of folic acid was suboptimal in $36.3 \%$ of this sample 
and non-consumption was more common in people with a low socioeconomic status. The prevalence of cleft lip and palate was 1.98 per 1000 births.

\section{Strengths and limitations}

This study is based on self-reported measures of folic acid consumption and does not contain information regarding formulation, dosage, or timing of initiation of folic acid. As the data were collected after delivery, it is possible that report bias has occurred; however, this bias will be, from the best of the authors' knowledge, nondirectional and will, therefore, not change the direction of the findings. The bias might affect the power of the study: this has been taken into account with a coherent sampling strategy, resulting in a large sample size. Maternal dietary factors and consumption of vitamins may also impact on the effect of folate on cleft lip and palate and women not taking folic acid supplements may be less likely to have healthier habits during pregnancy; these factors were not covered in the initial questionnaire in detail.

In addition, the caseness of cleft lip and palate was based on parental self-report. Based on the study governance of Growing Up in Ireland, it was not possible to validate against medical records. It is not likely that recall or report bias would change the direction of the association; however, as a potential link between folate and cleft lip and palate is not discussed in the media, public knowledge of it seems unlikely.

Difficulties in detecting population changes in rare conditions such as congenital anomalies limit studies trying to detect protective behaviours. Furthermore, it is not possible to rule out the effect of unknown confounders. The study design does allow an assessment of a statistical association between folate intake and cleft lip and palate, but no formal assessment of causality can be done. However, a major strength of this study is the large and representative nature of the sample, which equated to approximately one-seventh of all births in Ireland in 2007.15 This study's results take cleft lip and palate and cleft palate into account.

\section{Comparison with existing literature}

A study from England found that, although $88.9 \%$ of women reported taking folic acid supplements before their 18-week antenatal clinic appointment, $51.6 \%$ of those surveyed did not take folic acid supplement before 4 weeks' gestation. ${ }^{17}$ Internationally, in a systematic review of 52 studies, in some 20 (mainly Western) countries between 1992 and 2001, the reported periconceptional supplement use ranged from $0.5 \%$ to $52 \% .^{18}$

Similar to previous studies, these findings showed that not taking folic acid was more common in women of low socioeconomic status. An earlier Irish study using data collected from 300 women attending a maternity hospital found professional class and planned pregnancy to be the main predictors of periconceptional use of folic acid. ${ }^{10}$ A recent study from New Zealand found that younger maternal age, increasing parity, minority ethnic group, lower education, and lower income predicted poor folic acid intake in expectant mothers. ${ }^{19}$

The cleft lip and palate prevalence of approximately 1.98 per 1000 births was similar to that of a recent Dutch study, which reported a prevalence of 1.68 per 1000 births. ${ }^{20}$ Although there is no national registry of cleft lip and palate in Ireland, four regional Irish cleft lip and palate registers reported prevalence estimates between 1.17 and 2.02 per 1000 births in 2008-2009..$^{21}$ The current study is thought to be the first formal estimate of the prevalence of cleft lip and palate in a nationally representative Irish cohort.

Previous research from the International Database of Craniofacial Anomalies suggests that Ireland has a high rate of cleft lip and palate compared with the European average, which is reported as 1.4 per 1000 births (no $\mathrm{Cl}$ available).22 Similarly, the prevalence of cleft lip and palate in the UK ranges from 1.32 to 1.78 per 1000 births. ${ }^{17}$ It is of interest that the prevalence of cleft lip and palate was higher in northern Europe (1.73 per 1000 births) compared with its prevalence in southern Europe $(0.87$ per 1000 births), although no explanation for this has been suggested. ${ }^{22}$ Although promotion and awareness of the benefits of folic acid have been ongoing in Ireland over the last two decades, a concomitant reduction in the prevalence of neural tube defects has not been found. ${ }^{23}$

The potential protective effect of folic acid on cleft lip and palate, as illustrated in Figure 1 , is consistent with findings from a number of case-control studies, although significance levels vary considerably. A small Hungarian cohort control study found an insignificant $\mathrm{OR}$ of $1.00195 \% \mathrm{Cl}=0.20$ to 4.95), ${ }^{24}$ whereas another case-control study found an OR of $0.60(95 \% \mathrm{Cl}=0.39$ to 0.92$)$ with regard to the effect of folic acid supplementation on the rate of cleft lip and palate. ${ }^{25}$ The corresponding crude OR of 0.23 in this study is in line with the findings from the latter study, and comparable considering the $\mathrm{Cl}$ s used $(95 \% \mathrm{Cl}=0.08$ to 0.65$)$. 
In contrast to this study, a recent Cochrane review of the effect of folic acid on cleft lip or cleft palate found insufficient evidence to support the protective effect of folic acid. This was largely owing to insufficient cases of the defect occurring in the trials. ${ }^{5}$ The plausibility of folic acid in preventing cleft lip is indirectly supported by the higher prevalence of cleft lip and palate among pregnant women taking drugs that can act as folic acid antagonists, such as phenytoin and phenobarbitone. ${ }^{7}$

Previous research addressed confounding in several ways. Several studies included an adjusted OR, controlling for a wide range of variables including smoking, alcohol consumption, maternal age, education, employment during early pregnancy, sex of infant, year of infant's birth, family history of cleft lip and palate, maternal epilepsy and diabetes, and whether pregnancy was planned. 13,14 The adjusted OR in the present study did not differ significantly from the crude OR.

\section{Implications for practice}

This study supports the hypothesis that folic acid supplements play a significant role in preventing cleft lip and palate when taken in the first 12 weeks of pregnancy. Healthcare practitioners should be made aware of the growing benefits of folic acid and reinforce the importance of folic acid supplement education as part of prenatal counselling. This information is particularly pertinent to GPs as they are usually the first point of contact for women who are trying to conceive or in the very early stages of pregnancy. These findings suggest that folic acid plays a major role in preventing a major birth defect and, in addition, it is offers established protection against neural tube defects. 


\section{REFERENCES}

1. Mossey PA, Little J, Munger RG, et al. Cleft lip and palate. Lancet 2009; 374(9703): 1773-1785.

2. Natsume N, Kawai T, Ogi N, Yoshida W. Maternal risk factors in cleft lip and palate: case control study. Br J Oral Maxillofac Surg 2000; 38(1): 23-25.

3. Honein MA, Rasmussen SA, Reefhuis J, et al. Maternal smoking and environmental tobacco smoke exposure and the risk of orofacial clefts. Epidemiology 2007; 18(2): 226-233.

4. Tomson T, Battino D, Bonizzoni E, et al. Dose-dependent risk of malformations with antiepileptic drugs: an analysis of data from the EURAP epilepsy and pregnancy registry. Lancet Neurol 2011; 10(7): 609-617.

5. De-Regil LM, Fernández-Gaxiola AC, Dowswell T, Peña-Rosas JP. Effects and safety of periconceptional folate supplementation for preventing birth defects. Cochrane Database Syst Rev Issue 2010; (10): CD007950.

6. Ionescu-Ittu R, Marelli AJ, Mackie AS, Pilote L. Prevalence of severe congenital heart disease after folic acid fortification of grain products: time trend analysis in Quebec, Canada. BMJ 2009; 338: b1673

7. Molloy AM, Scott JM. Folates and prevention of disease. Public Health Nutr 2001; 4(2B): 601-609.

8. Beaudin AE, Stover PJ. Insights into metabolic mechanisms underlying folateresponsive neural tube defects: a minireview. Birth Defects Res A Clin Mol Teratol 2009; 85(4): 274-284.

9. Report of the implementation group on folic acid food fortification to the Department of Health and Children. Dublin: Food Safety Authority of Ireland, 2008.

10. McDonnell R, Johnson Z, Doyle A, Sayers G. Determinants of folic acid knowledge and use among antenatal women. J Public Health Med 1999; 21(2): 145-149.

11. McGuire M, Cleary B, Sahm L, Murphy DJ. Prevalence and predictors of periconceptional folic acid uptake-prospective cohort study in an Irish urban obstetric population. Hum Reprod 2010; 25(2): 535-543.

12. Stockley $L$, Lund V. Use of folic acid supplements, particularly by low-income and young women: a series of systematic reviews to inform public health policy in the UK. Public Health Nutr 2008; 11(8): 807-821.

13. Johnson CY, Little J. Folate intake, markers of folate status and oral clefts: is the evidence converging? Int J Epidemiol 2008; 37(5): 1041-1058.

14. Badovinac RL, Werler MM, Williams PL, et al. Folic acid-containing supplement consumption during pregnancy and risk for oral clefts: a meta-analysis. Birth Defects Res A Clin Mol Teratol 2007; 79(1): 8-15.

15. Quail A, Williams J, McCrory C, et al. Sample design and response in wave 1 of the infant cohort (at 9 months) of Growing Up in Ireland. Dublin: Department of Health and Children, April 2011

16. Quail A, Williams J, McCrory C, et al. A summary guide to wave 1 of the infant cohort lat 9 months) of Growing Up in Ireland. Dublin: Department of Health and Children, April 2011.

17. Relton CL, Hammal DM, Rankin J, Parker L. Folic acid supplementation and social deprivation. Public Health Nutr 2005; 8(3): 338-340.

18. Ray JG, Singh G, Burrows RF. Evidence for suboptimal use of periconceptional folic acid supplements globally. BJOG 2004; 111(5): 399-408.

19. Mallard SR, Gray AR, Houghton LA. Delaying mandatory folic acid fortification policy perpetuates health inequalities: results from a retrospective study of postpartum New Zealand women. Hum Reprod 2011; 27(1): 273-282

20. Rozendaal AM, Luijsterburg AJ, Ongkosuwito EM, et al. Decreasing prevalence of oral cleft live births in the Netherlands, 1997-2006. Arch Dis Child Fetal Neonatal Ed 2011: 96(3): F212-216.

21. European Surveillance of Cogenital Anomalies Data (EUROCAT). 2011. http://unw.eurocat-network.eu/accessprevalencedata/prevalencetables laccessed 6 Jun 2012).

22. IPDTOC Working Group. Prevalence at Birth of Cleft Lip With or Without Cleft Palate: Data From the International Perinatal Database of Typical Oral Clefts (IPDTOC). Cleft Palate Craniofac J 2011; 48(1): 66-81.

23. Ward M, Hutton J, Mc Donnell R, et al. Folic acid supplements to prevent neural tube defects: trends in East of Ireland 1996-2002. Ir Med J 2004; 97(9): 274-276.

24. Czeizel AE, Dobó M, Vargha P. Hungarian cohort-controlled trial of periconceptional multivitamin supplementation shows a reduction in certain congenital abnormalities. Birth Defects Res A Clin Mol Teratol 2004; 70(11): 853-861.

25. Van Rooij IA, Ocké MC, Straatman H, et al. Periconceptional folate intake by supplement and food reduces the risk of nonsyndromic cleft lip with or without cleft palate. Prev Med 2004: 39(4): 689-694. 